\title{
Switching or blinking? - The switching behaviour of single photochromic triads
}

\author{
Johannes Maier ${ }^{1, *}$, Martti Pärs ${ }^{1}$, Tina Weller ${ }^{2}$, Mukundan Thelakkat ${ }^{2}$, and Jürgen Köhler ${ }^{1}$ \\ ${ }^{1}$ Spectroscopy of soft Matter, University of Bayreuth, 95447 Bayreuth, Germany \\ ${ }^{2}$ Applied Functional Polymers, University of Bayreuth, 95447 Bayreuth, Germany
}

\begin{abstract}
Photochromic molecules can be interconverted between two bistable conformations by light [1-3]. Irie and coworkers described a strategy to achieve superior fluorescence characteristics and outstanding switching characteristics of a photochromic unit by linking strong fluorophores covalently to photochromic building blocks $[3,4]$. Accordingly, we synthesised molecular triads that consist of two perylene bisimide (PBI) fluorophores covalently linked to a dithienylcyclopentene (DCP) photochromic switch, see fig. 1. Such kinds of triads are promising candidates for super-resolution microscopy like RESOLFT and PALM [5,6], or can be used as optical transistors or memories [4,7].
\end{abstract}

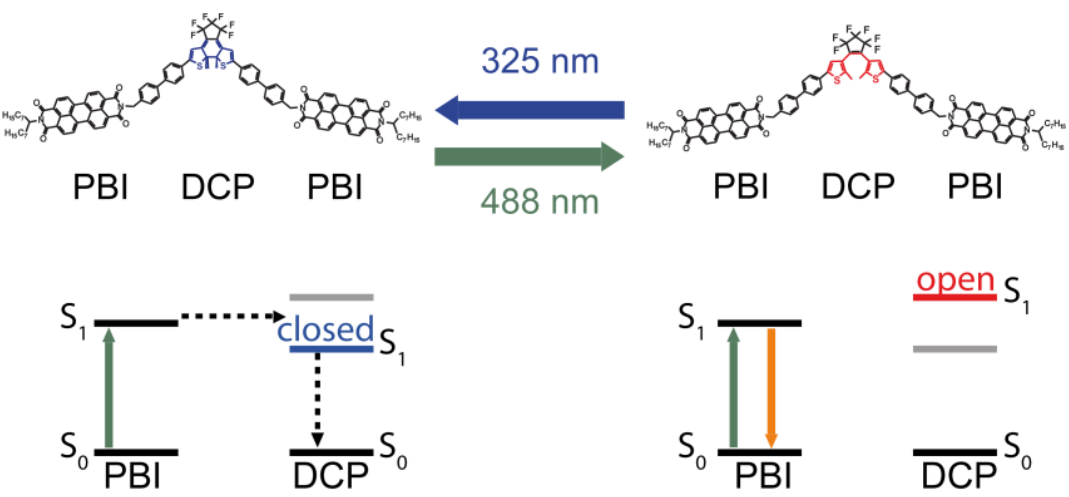

Fig. 1. Top: closed (left) and open (right) state of the photoswitchable triad PBI-DCP-PBI, where the closed state is reached via illumination in the UV spectral range $(325 \mathrm{~nm})$ and the open state is reached via illumination in the visible range $(488 \mathrm{~nm})$. Bottom: Energy level scheme of the closed (left) and open (right) state of the triad. In the closed state, the excited state of the switch DCP lies below the excited state of the PBI, energy transfer is possible and the fluorescence of the PBI is reduced, whereas in the open state of the switch, energy transfer is not possible and the PBI shows fluorescence.

Regarding super-resolution microscopy and a demand for miniaturization for transistors and memories, single molecule applications are of great interest [8]. When studying the

\footnotetext{
*Corresponding author: joh.maier@uni-bayreuth.de
} 
fluorescence of single photochromic triads under simultaneous illumination of visible and UV light, the on/off-durations of the telegraph-like fluorescence intensity vary as a function of the UV intensity [9]. The problem faced is that it is impossible to discriminate between off-states that are due to illumination with UV light and those that are due to spontaneous, yet unwanted and unavoidable blinking processes. However, a statistical analysis allows to determine the probability for transitions to the off state by deliberate switching of the triad. Such an analysis yields the positive predictive value $\mathrm{p}(\mathrm{S} \mid+)$, that corresponds to the conditional probability that the triad indeed has been switched (S) given that a delay $(+)$ between the onset of the excitation laser and the onset of the fluorescence has been observed. For the 15 triads we examined, this probability amounts on average to $0.8 \pm 0.1$ with a maximum of approximately 0.96 [10], sufficiently large for application in superresolution microscopy.

\section{References}

1. H. Bouas-Laurent, H. Dürr, Pure and Applied Chemistry, 73, 639 (2001)

2. B.L. Feringa, Molecular Switches (Wiley-VCH, Weinheim, 2001)

3. M. Irie, T. Fukaminato, K. Matsuda, S. Kobatake, Chem. Rev., 114, 12174 (2014)

4. M. Irie, Chem. Rev., 100, 1685 (2000)

5. O. Nevskyi, D. Sysoiev, J. Dreier, S.C. Stein, A. Oppermann, F. Lemken T. Janke, J. Enderlein, I. Testa, T. Huhn, D. Wöll, Small, 14, 1703333 (2018)

6. M. Irie, M. Morimoto, BCSJ, 91, 237 (2018)

7. M. Pärs, C.C. Hofmann, K. Willinger, P. Bauer, M. Thelakkat, J. Köhler, Angew. Chem. Int. Ed., 50, 11405 (2011)

8. M. Irie, T. Fukaminato, T. Sasaki, N. Tamai, T. Kawai, Nature, 420, 759 (2002)

9. T. Fukaminato, T. Umemoto, Y. Iwata, S. Yokojima, M. Yoneyama, S. Nakamura, M. Irie, J. Am. Chem. Soc., 129, 5932 (2007)

10. J. Maier, M. Pärs, T. Weller, M. Thelakkat, J. Köhler, Sci. Rep., 7, 41739 (2017) 